\title{
Resistance of Musca domestica L. Populations to Cyromazine (Insect Growth Regulator) in Brazil
}

\author{
Mara Cristina Pinto ${ }^{+}$, Angelo Pires do Prado
}

\begin{abstract}
Departamento de Parasitologia, Instituto de Biologia, Universidade Estadual de Campinas, Cidade Universitária s/n, Caixa Postal 6109, 13083-970 Campinas, SP, Brasil
\end{abstract}

Five field populations of Musca domestica L. collected in poultry farms were bioassayed in order to detect possible resistance to the larvicide cyromazine in Brazil. The concentrations used were 0, 0.5, 0.1, 0.2, 0.4, 1, 2, 4 and 8 ppm. Three populations (Petrópolis, RJ, Montes Claros, MG and Promissão, $S P$ ) were resistant, while the other two populations (Ibiuna, SP and Monte Mor, SP) were more susceptible than the reference pathern used by the World Health Organization. The presence of three resistant house fly populations to cyromazine in Brazilian poultry farms strongly suggests that the operational aspects of larvicide use are important for the resistance development. Cyromazine is applied as a feedthrough, both in Brazil and in the USA, where resistance has already been documented. However, in Denmark, where it was approved only as a topical manure spray, no case of resistance has yet been detected.

Key words: Musca domestica - larvicide - resistance - insect growth regulator - cyromazine - poultry farms

Insect growth regulators (IGR) were believed to be on the safe side regarding the evolution of resistance (Williams 1967). However, various studies have shown that resistance can evolve in response to this chemical group (Cerf \& Georghiou 1972, Dyte 1972), moreover if the selection pressure is sufficiently strong (Keiding 1999). The method of insecticide application is an operational factor that can induce the resistance development.

Cyromazine (N-cyclopropyl-1,3,5-triazine2,4,6-triamine) is a new class of IGR derived from azidotriazine herbicides (Shen \& Plapp 1990) causing death to larvae or deformation to pupae (Friedel $\&$ McDonell 1985). In poultry farms it has been used for the control of manure-breeding flies, (especially house flies Musca domestica L.) in two ways: feed-through larvicide or as a spray applied over the manure.

Since cyromazine feed-through was first used in USA poultry farms in the 80 s, reports have shown the development of resistance or tolerance in populations of house flies (Iseki \& Georghiou 1986, Bloomcamp et al. 1987, Sheppard et al. 1989, 1992). In Danish poultry farms, however, where it has been used as a topical manure spray since 1984,

\footnotetext{
${ }^{+}$Corresponding author. Fax: +55-41-322.4334. E-mail: marapinto@hotmail.com Received 14 August 2000 Accepted 29 November 2000
}

no case of resistance in house flies has been documented (Jespersen 1990, Keiding et al. 1992).

In Brazil, this product has also been used since 1984 as a feed-through although no study has been carried out to assess the susceptibility of $M$. domestica. In 1992, with the objective of evaluating the level of susceptibility to cyromazine in this country, we compared five house fly field populations through the use of a dose-response test.

\section{MATERIALS AND METHODS}

Maintenance of insects - House flies were captured using an entomological net in five widely separated poultry farms situated at the following Brazilian cities: Petrópolis, RJ, Promissão, SP, Ibiuna, SP, Monte Mor, SP and Montes Claros, MG. In these farms, cyromazine had been carried out for six to eight years and problems controlling the house flies had been observed. In the laboratory, $M$. domestica adults were separated from the other flies and fed a 1:1:1 mixture of sugar, powdered milk and yeast. Eggs of the second or third generation were collected from cages and cultured in a fermented larval medium which consisted of $35 \%$ of animal ration plus $65 \%$ parts of water.

Bioassay - Cyromazine (Ciba), a powdered product, was dissolved in the water used to make the larval medium. Initially, cyromazine was applied to all five populations in concentrations of 1 , 2, 4 and 8 parts per million (ppm). Two populations (Monte Mor and Ibiuna) which had $100 \%$ of mortality in $1 \mathrm{ppm}$, were retested with the following concentrations: $0.05,0.1,0.2$ and $0.4 \mathrm{ppm}$. Treated medium was allocated in plastic contain- 
ers with $100 \mathrm{~g}$ in each, with each concentration replicated four times. Untreated medium was used as a control, with the same number of replications. Samples of 100 larvae obtained a few hours after hatching were placed in each container.

Tests were kept in a growth chamber at $27 \pm 1^{\circ} \mathrm{C}$, $75 \% \mathrm{RH}$ and constant photoperiod (12/12).

After eight days pupae were collected by flotation in water and maintained at the same conditions described for larvae during seven more days until the adults emergence, when they were counted.

The cyromazine concentrations that killed 50\% and $95 \%$ of the number of larvae tested $\left(\mathrm{LC}_{50}\right.$, $\mathrm{LC}_{95}$ ) for each population were calculated by hand using Probit Analysis (Finney 1971). Control mortality was used to correct the net mortality (Abbott 1925). The resistance ratio (RR) to cyromazine was calculated by dividing the $\mathrm{LC}_{50}$ for the population tested by the $\mathrm{LC}_{50}$ for the World Health Organization (WHO) susceptible population.

\section{RESULTS}

Bioassays indicated the presence of resistance to cyromazine in three out of five house fly populations at different sites in Brazil. Populations from Petrópolis, Montes Claros and Promissão were resistant to cyromazine whereas the populations from Ibiuna and Monte Mor were even more sensitive than the WHO susceptible pattern (Table I). RR varied from 12.8 fold on the most resistant population to 0.24 fold on the most sensitive population.

The confidence intervals at $\mathrm{LC}_{50}$ of the two most resistant populations, Petrópolis and Montes

\section{TABLE I}

$\mathrm{LC}_{50}, \mathrm{LC}_{95}( \pm \mathrm{CI})$ and resistance ratios of cyromazine for five populations of Musca domestica

\begin{tabular}{lccc}
\hline Populations & $\mathrm{LC}_{50}{ }^{a}$ & $\mathrm{LC}_{95}$ & $\mathrm{RR}^{b}$ \\
\hline Petrópolis & 3.19 & 12.90 & 12.8 \\
& $(2.86-3.57)$ & $(10.81-15.41)$ & \\
Montes Claros & 2.80 & 7.28 & 11.2 \\
& $(2.60-2.98)$ & $(6.70-7.91)$ & \\
Promissão & 1.62 & 2.91 & 6.5 \\
& $(1.49-1.76)$ & $(2.67-3.16)$ & \\
Ibiuna & 0.10 & 0.16 & 0.40 \\
& $(0.09-0.11)$ & $(0.14-0.17)$ & \\
Monte Mor & 0.06 & 0.29 & 0.24 \\
& $(0.05-0.07)$ & $(0.25-0.30)$ & \\
\hline
\end{tabular}

$a$ : concentration in ppm; $b: \mathrm{LC}_{50}$ for population tested/ 0.25 -WHO susceptible pattern
Claros, overlapped indicating indistinguishable levels of resistance. However an intermediate level of resistance was detected on Promissão population when compared to the two most resistant and the two most sensitive populations (Figure).

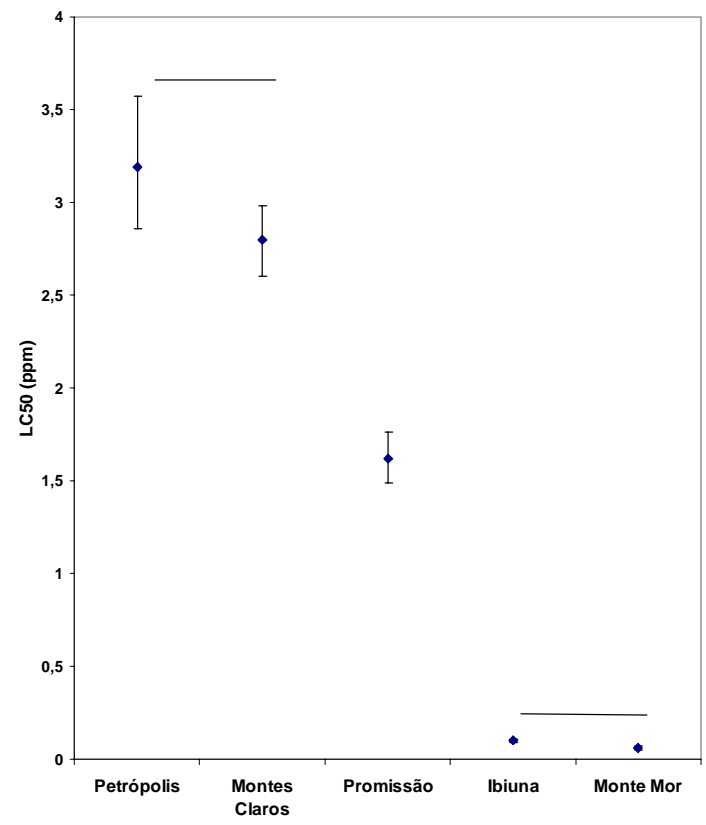

$\mathrm{LC}_{50}( \pm \mathrm{CI})$ of cyromazine for five house fly populations. The bars linking Petrópolis-Montes Claros and Ibiuna-Monte Mor indicate the same level of resistance.

\section{DISCUSSION}

The term "resistance" is used in this paper with the same reservations expressed by Pap and Farkas (1994). According to these authors resistance is a genetic phenomenon that should be studied in an intergeneration context, and the lethal concentrations relate only phenotypic tolerance. In spite of this, the use of the term "resistance" has been widely used in an operational sense.

Our study detected for the first time the presence of resistance to cyromazine in Brazil in three out of five house fly populations evaluated. However, it is not possible to explain these differences found in terms of the history of cyromazine application in each site, as in all poultry farms surveyed, cyromazine had been applied as a feed-through for six years on the two sensitive populations, and one or two years more on the others.

The interaction between insects and insecticides involves genetic, biological and operational factors (Georghiou \& Taylor 1977a,b) and the demonstration of resistance in a certain local may just reflect a temporary situation. Seasonal variation and metapopulation model studies suggest this provi- 
sional condition. Progenies of $M$. domestica collected during a year showed seasonal variation in sensitivity to insecticides (Oliveira et al. 1993). In a metapopulation model, a large stable population is subdivided into many local populations, each of which is unstable. Extinction and recolonization events can increase genetic differentiation among populations (Caprio \& Hoy 1994).

Apart from the temporary aspects mentioned above, related to the documentation of resistance, the methodology applied on bioassay may also be highlighted. The use of dose/response is an adequate way to document resistance that has reached high levels, but is inefficient for detection of an incipient resistance outbreak (Roush \& Miller 1986). It is possible, therefore, that the two sensitive populations have resistant genes in low frequencies.

The method of cyromazine application in Brazilian poultry farms is the same as that used in the USA, namely feed-through. Bloomcamp et al. (1987) detected resistance in one Florida poultry farm where cyromazine had been used for two seasons. Sheppard et al. (1992) found that, in one Mississipi poultry farm house, flies became three times more resistant after two years of cyromazine use. Moderate to high resistance to cyromazine develops if the selection pressure is strong enough, as in the case of feed-through treatments (Keiding 1999).

It is of particular significance to this study that resistance has not been shown (as yet) in Denmark. In that country, cyromazine has not been authorized for use as a feed-through; it has been used only as a topical manure spray (Keiding et al. 1992). The direct treatment of the manure leaves some parts without larvicide, permitting the survival of susceptible individuals to dilute the resistance (Sheppard et al. 1989).

As stressed by Axtell (1986), an integrated control program in poultry farms requires cultural, biological and chemical methods, however fly resistance to insecticides often develops rapidly and many chemicals used in the past are no longer effective. Cyromazine is a powerful chemical method because cross-resistance with other conventional insecticides, e.g. organophosphorous and pyretroids has not yet been found in the various countries it has been used, such as the USA (Iseki \& Georghiou 1986), Denmark (Keiding et al. 1991), Hungary (Pap \& Farkas 1994) and Germany (Pospischil et al. 1996). Adding this advantage to ways of delaying or avoiding resistance make this larvicide an useful tool for house fly control. This study gives additional support to the importance of the operational methods of cyromazine application on the resistance process development.

\section{ACKNOWLEGMENTS}

To Diarmid Campbell Lendrum and Marcelo Duarte for helpful comments on the manuscript.

\section{REFERENCES}

Axtell RC 1986. Fly management in poultry production: cultural, biological an chemical. Poultry Science 65: 657-667.

Abbott WS 1925. A method of computing the effectiveness of an insecticide. J Econ Entomol 18: 265-267.

Bloomcamp CL, Patterson RS, Koehler PG 1987. Cyromazine resistance in the house fly (Diptera: Muscidae). J Econ Entomol 80: 352-357.

Caprio MA, Hoy MA 1994. Metapopulation dynamics affect resistance development in the predatory mite, Metaseiulus occidentalis (Acari: Phytoselidae). J Econ Entomol 87: 525-534.

Cerf DC, Georghiou GP 1972. Evidence of cross-resistance to a juvenile hormone analogue in some insecticide resistant house flies. Nature 239: 401-402.

Dyte CE 1972. Resistance to synthetic juvenile hormone in a population of the flour beetle, Triboliumm castaneum. Nature 238: 48-49.

Finney DJ 1971. Probit Analysis, 3rd ed., University of Cambridge, $236 \mathrm{pp}$.

Friedel T, McDonell PA 1985. Cyromazine inhibits reproduction and larval development of the Australian sheep blowfly (Diptera: Calliphoridae). J Econ Entomol 78: 868-873.

Georghiou GP, Taylor CE 1977a. Genetic and biological influences in the evolution of resistance. $J$ Econ Entomol 70: 319-323.

Georghiou GP, Taylor CE 1977b. Operational influences in the evolution of insecticide resistance. $J$ Econ Entomol 70: 653-658.

Iseki A, Georghiou GP 1986. Toxicity of cyromazine to populations of the house fly (Diptera: Muscidae) variously resistant to insecticides. J Econ Entomol 79: 1192-1195.

Jespersen JB 1990. Susceptibility to the larvicides diflubenzuron and cyromazine. In Danish Pest Infestation Laboratory Annual Report, p. 46-47.

Keiding J 1999. Review of the global status and recent development of insecticide resistance in field populations of the house fly, Musca domestica (Diptera: Muscidae). Bull Entomol Res 89(Suppl. 1): S9-S67.

Keiding J, Jespersen JB, El-Khodary AS 1991. Resistance risk of two insect development inhibitors, diflubenzuron and cyromazine, for control of the house fly Musca domestica. Part I: larvicidal tests with insecticide-resistant laboratory and Danish field populations. Pestic Sci 32: 187-206.

Keiding J, El-Khodary AS, Jespersen JB 1992. Resistance risk assessment and cyromazine, for control of the house fly Musca domestica L. Part II: effects of selection pressure in laboratory and field populations. Pestic Sci 35: 27-37.

Oliveira PCS, Trevijano LKG, Bello M 1993. Sensibilidade estacional em linhagens de Musca domestica L. para três tipos de inseticidas. An Soc Entomol Bras 22: 455-461.

Pap L, Farkas R 1994. Monitoring of resistance of in- 
secticides in house fly Musca domestica populations in Hungary. Pestic Sci 40: 245-258.

Pospischil R, Szomm K, Londershausen M, Schroder I, Turberg A, Fuchs R 1996. Multiple resistance in the larger house fly Musca domestica in Germany. Pestic Sci 48: 333-341.

Roush RT, Miller GL 1986. Considerations for design of insecticide resistance monitoring programs. $J$ Econ Entomol 79: 293-298.

Shen J, Plapp Jr FW 1990. Cyromazine resistance in the house fly (Diptera: Muscidae): genetics and cross-resistance to diflubenzuron. J Econ Entomol
83: 1689-1697.

Sheppard DC, Ninkle NC, Hunter JSIII, Gaydon DM 1989. Resistance in constant exposure livestock insect control systems: a partial review with some original findings on cyromazine resistance in house flies. Fla Entomol 72: 360-369.

Sheppard DC, Gaydon DM, Miller RW 1992. Resistance in house fllies (Diptera: Muscidae) selected with 5,0 ppm feed-through cyromazine. J Econ Entomol 9: 257-260.

Williams CM 1967. Third-generation pesticides. Sci Am 217: $13-17$. 